Claremont Colleges

Scholarship@ Claremont

Pitzer Faculty Publications and Research

Pitzer Faculty Scholarship

$10-1-1988$

\title{
The Centrality of Mathematics in the History of Western Thought
}

Judith V. Grabiner

Pitzer College

\section{Recommended Citation}

Grabiner, Judith V. "The Centrality of Mathematics in the History of Western Thought." Mathematics Magazine 61.4 (October 1988): 220-230.

This Article is brought to you for free and open access by the Pitzer Faculty Scholarship at Scholarship @ Claremont. It has been accepted for inclusion in Pitzer Faculty Publications and Research by an authorized administrator of Scholarship @ Claremont. For more information, please contact scholarship@cuc.claremont.edu. 


\title{
The Centrality of Mathematics in the History of Western Thought*
}

\author{
JUDITHV. GRABINER \\ Pitzer College \\ Claremont, CA 91711
}

1. Introduction Since this paper was first given to educators, let me start with a classroom experience. It happened in a course in which my students had read some of Euclid's Elements of Geometry. A student, a social science major, said to me, "I never realized mathematics was like this. Why, it's like philosophy!" That is no accident, for philosophy is like mathematics. When I speak of the centrality of mathematics in western thought, it is this student's experience I want to recapture-to reclaim the context of mathematics from the hardware store with the rest of the tools and bring it back to the university. To do this, I will discuss some major developments in the history of ideas in which mathematics has played a central role.

I do not mean that mathematics has by itself caused all these developments; what I do mean is that mathematics, whether causing, suggesting, or reinforcing, has played a key role; it has been there, at center stage. We all know that mathematics has been the language of science for centuries. But what I wish to emphasize is the crucial role of mathematics in shaping views of man and the world held not just by scientists, but by everyone educated in the western tradition.

Given the vastness of that tradition, I will give many examples only briefly, and be able to treat only a few key illustrative examples at any length. Sources for the others may be found in the bibliography. (See also [26].)

Since I am arguing for the centrality of mathematics, I will organize the paper around the key features of mathematics which have produced the effects I will discuss. These features are the certainty of mathematics and the applicability of mathematics to the world.

2. Certainty For over two thousand years, the certainty of mathematics, particularly of Euclidean geometry, has had to be addressed in some way by any theory of knowledge. Why was geometry certain? Was it because of the subject matter of geometry, or because of its method? And what were the implications of that certainty?

Even before Euclid's monumental textbook, the philosopher Plato saw the certainty of Greek geometry - a subject which Plato called "knowledge of that which always is" [41, 527b] — as arising from the eternal, unchanging perfection of the objects of mathematics. By contrast, the objects of the physical world were always coming into being or passing away. The physical world changes, and is thus only an approximation to the higher ideal reality. The philosopher, then, to have his soul drawn from the changing to the real, had to study mathematics. Greek geometry fed Plato's idealistic philosophy; he emphasized the study of Forms or Ideas transcending experience: the idea of justice, the ideal state, the idea of the Good. Plato's views were used by philosophers within the Jewish, Christian, and Islamic traditions to deal with how a divine being, or souls, could interact with the material world [46, pp. 382-3] [51, pp. $17-40][34$, p. 305ff] [23, p. 46-67]. For example, Plato's account of the creation of the world in his Timaeus, where a god makes the physical universe by copying an

*CInternational Congress of Mathematicians, 1986, Berkeley, California 
ideal mathematical model, became assimilated in early Christian thought to the Biblical account of creation [29, pp. 21-22]. One finds highly mathematicized cosmologies, influenced by Plato, in the mystical traditions of Islam and Judaism as well. The tradition of Platonic Forms or Ideas crops up also in such unexpected places as the debates in eighteenth- and nineteenth-century biology over the fixity of species. Linnaeus in the eighteenth, and Louis Agassiz in the nineteenth century seem to have thought of species as ideas in the mind of God [16, p. 34] [13, pp. 36-7]. When we use the common terms "certain" and "true" outside of mathematics, we use them in their historical context, which includes the long-held belief in an unchanging reality-a belief stemming historically from Plato, who consistently argued for it using examples from mathematics.

An equally notable philosopher, who lived just before Euclid, namely Aristotle, saw the success of geometry as stemming, not from perfect eternal objects, but instead from its method [Posterior Analytics, I 10-11; I 1-2 (77a5, 71b ff)] [19, vol. I, Chapter IX]. The certainty of mathematics for Aristotle rested on the validity of its logical deductions from self-evident assumptions and clearly-stated definitions. Other subjects might come to share that certainty if they could be understood within the same logical form; Aristotle, in his Posterior Analytics, advocated reducing all scientific discourse to syllogisms, that is, to logically-deduced explanations from first principles. In this tradition, Archimedes proved the law of the lever, not by experiments with weights, but from deductions à la Euclid from postulates like "equal weights balance at equal distances" [18, pp. 189-194]. Medieval theologians tried to prove the existence of God in the same way. This tradition culminates in the 1675 work of Spinoza, Ethics Demonstrated in Geometrical Order, with such axioms as "That which cannot be conceived through another must be conceived through itself," definitions like "By substance I understand that which is in itself and conceived through itself" (compare Euclid's "A point is that which has no parts"), and such propositions as "God or substance consisting of infinite attributes ... necessarily exists," whose proof ends with a QED [48, pp. 41-50]. Isaac Newton called his famous three laws "Axioms, or Laws of Motion." His Principia has a Euclidean structure, and the law of gravity appears as Book III, Theorems VII and VIII [37, pp. 13-14, pp. 414-17]. The Declaration of Independence of the United States is one more example of an argument whose authors tried to inspire faith in its certainty by using the Euclidean form. "We hold these truths to be self-evident..." not that all right angles are equal, but "that all men are created equal." These self-evident truths include that if any government does not obey these postulates, "it is the right of the people to alter or abolish it." The central section begins by saying that they will "prove" King George's government does not obey them. The conclusion is "We, therefore... declare, that these United Colonies are, and of right ought to be, free and independent states." (My italics) (Jefferson's mathematical education, by the way, was quite impressive by the standards of his time.)

Thus a good part of the historical context of the common term "proof" lies in Euclidean geometry - which was, I remind you, a central part of Western education.

However, the certainty of mathematics is not limited to Euclidean geometry. Between the rise of Islamic culture and the eighteenth century, the paradigm governing mathematical research changed from a geometric one to an algebraic, symbolic one. In algebra even more than in the Euclidean model of reasoning, the method can be considered independently of the subject-matter involved. This view looks at the method of mathematics as finding truths by manipulating symbols. The approach first enters the western world with the introduction of the Hindu-Arabic 
number system in the twelfth-century translations into Latin of Arabic mathematical works, notably al-Khowarizmi's algebra. The simplified calculations using the HinduArabic numbers were called the "method of al-Khowarizmi" or as Latinized "the method of algorism" or algorithm.

In an even more powerful triumph of the heuristic power of notation, François Viète in 1591 introduced literal symbols into algebra: first, using letters in general to stand for any number in the theory of equations; second, using letters for any number of unknowns to solve word problems [4, pp. 59-63, 65]. In the seventeenth century, Leibniz, struck by the heuristic power of arithmetical and algebraic notation, invented such a notation for his new science of finding differentials - an algorithm for manipulating the $d$ and integral symbols, that is, a calculus (a term which meant to him the same thing as "algorithm" to us). Leibniz generalized the idea of heuristic notation in his philosophy [30, pp. 12-25]. He envisioned a symbolic language which would embody logical thought just as these earlier symbolic languages enable us to perform algebraic operations correctly and mechanically. He called this language a "universal characteristic," and later commentators, such as Bertrand Russell, see Leibniz as the pioneer of symbolic logic [45, p. 170]. Any time a disagreement occurred, said Leibniz, the opponents could sit down and say "Let us calculate," and-mechanically - settle the question [30, p. 15]. Leibniz's appreciation of the mechanical element in mathematics when viewed as symbolic manipulation is further evidenced by his invention of a calculating machine. Other seventeenth-century thinkers also stressed the mechanical nature of thought in general: for instance, Thomas Hobbes wrote "Words are wise men's counters, they do but reckon by them" [21, Chapter 4, p. 143]. Others tried to introduce heuristically powerful notation in different fields: consider Lavoisier's new chemical notation which he called a "chemical algebra" [14, p. 245].

These successes led the great prophet of progress, the Marquis de Condorcet, to write in $\mathbf{1 7 9 3}$ that algebra gives "the only really exact and analytical language yet in existence... . Though this method is by itself only an instrument pertaining to the science of quantities, it contains within it the principles of a universal instrument, applicable to all combinations of ideas" [9, p. 238]. This could make the progress of "every subject embraced by human intelligence... as sure as that of mathematics" [9, pp. 278-9]. The certainty of symbolic reasoning has led us to the idea of the certainty of progress. Though one might argue that some fields had not progressed one iota beyond antiquity, it was unquestionably true by 1793 that mathematics and the sciences had progressed. To quote Condorcet once more: "the progress of the mathematical and physical sciences reveals an immense horizon... a revolution in the destinies of the human race" [9, p. 237]. Progress was possible; why not apply the same method to the social and moral spheres as well?

No account of attempts to extend the method of mathematics to other fields would be complete without discussing René Descartes, who in the 1630's combined the two methods we have just discussed - that of geometry and that of algebra-into analytic geometry. Let us look at his own description of how to make such discoveries. Descartes depicted the building-up of the deductive structure of a science-proof-as a later task than analysis or discovery. One first needed to analyze the whole into the correct "elements" from which truths could later be deduced. "The first rule," he wrote in his Discourse on Method, "was never to accept anything as true unless I recognized it to be evidently such... The second was to divide each of the difficulties which I encountered into as many parts as possible, and as might be required for an easier solution..." Then, "the third [rule] was to [start]... with the things which 
were simplest and easiest to understand, gradually and by degrees reaching toward more complex knowledge" [10, Part II, p. 12]. Descartes presented his method as the key to his own mathematical and scientific discoveries. Consider, for instance, the opening line of his Geometry: “All problems in geometry can easily be reduced to such terms that a knowledge of the lengths of certain straight lines suffices for their construction. Just as arithmetic is composed of only four or five operations..., so in geometry" [11, Book I, p. 3]. Descartes's influence on subsequent philosophy, from Locke's empiricism to Sartre's existentialism, is well known and will not be reviewed here. But for our purposes it is important to note that the thrust of Descartes's argument is that emulating the method successful in mathematical discovery will lead to successful discoveries in other fields [10, Part Five].

Descartes' method of analysis fits nicely with the Greek atomic theory, which had been newly revived in the seventeenth century: all matter is the sum of atoms; analyze the properties of the whole as the sum of these parts [17, Chapter VIII, esp. p. 217]. Thus the idea of studying something by "analysis" was doubly popular in seventeenth- and eighteenth-century thought. I would like to trace just one line of influence of this analytic method. Adam Smith in his 1776 Wealth of Nations analyzed $[47$, p. 12] the competitive success of economic systems by means of the concept of division of labor. The separate elements, each acting as efficiently as possible, provided for the overall success of the manufacturing process; similarly, each individual in the whole economy, while striving to increase his individual advantages, is "led as if by an Invisible Hand to promote ends which were not part of his original intention" [47, p. 27] - that is, the welfare of the whole of society. This Cartesian method of studying a whole system by analyzing it into its elements, then synthesizing the elements to produce the whole, was especially popular in France. For instance, Gaspard François de Prony had the job of calculating, for the French Revolutionary government, a set of logarithmic and trigonometric tables. He, himself, said he did it by applying Adam Smith's ideas about the division of labor. Prony organized a group of people into a hierarchical system to compute these tables. A few mathematicians decided which functions to use; competent technicians then reduced the job of calculating the functions to a set of simple additions and subtractions of pre-assigned numbers; and, finally, a large number of low-level human "calculators" carried out the additions and subtractions. Charles Babbage, the early nineteenth-century pioneer of the digital computer, applied the Smith-Prony analysis and embodied it in a machine [1, Chapter XIX]. The way Babbage's ideas developed can be found in a chapter in his Economy of Machinery entitled "On the Division of Mental Labour" [1, Chapter XIX]. Babbage was ready to convert Prony's organization into a computing machine because Babbage had long been impressed by the arguments of Leibniz and his followers on the power of notation to make such mathematical calculation mechanical, and Babbage, like Leibniz, accounted for the success of mathematics by "the accurate simplicity of its language" [22, p. 26]. Since Babbage's computer was designed to be "programmed" by punched cards, Hollerith's later invention of punched-card census data processing, twentieth-century computing, and other applications of the Cartesian "divide-and-solve" approach, including top-down programming, are also among the offspring of Descartes's mathematically-inspired method.

Whatever view of the cause of the certainty of mathematics one adopts, the fact of certainty in itself has had consequences. The "fact of mathematical certainty" has been taken to show that there exists some sort of knowledge, and thus to refute skepticism. Immanuel Kant in 1783 used such an argument to show that metaphysics is possible [25, Preamble, Section IV]. If metaphysics exists, it is independent of 
experience. Nevertheless, it is not a complex of tautologies. Metaphysics, for Kant, had to be what he called "synthetic," giving knowledge based on premises which is not obtainable simply by analyzing the premises logically. Is there such knowledge? Yes, said Kant, look at geometry. Consider the truth that the sum of the angles of a triangle is two right angles. We do not get this truth by analyzing the concept of triangle-all that gives us, Kant says, is that there are three angles. To gain the knowledge, one must make a construction: draw a line through one vertex parallel to the opposite side. (I now leave the proof as an exercise.) The construction is essential; it takes place in space, which Kant sees as a unique intuition of the intellect. (This example [24, II "Method of Transcendentalism," Chapter I, Section I, p. 423] seems to require the space to be Euclidean; I will return to this point later on.) Thus synthetic knowledge independent of experience is possible, so metaphysics-skeptics like David Hume to the contrary-is also possible.

This same point-that mathematics is knowledge, so there is objective truth-has been made throughout history, from Plato's going beyond Socrates' agnostic critical method, through George Orwell's hero, Winston Smith, attempting to assert, in the face of the totalitarian state's overwhelming power over the human intellect, that two and two are four.

Moreover, since mathematics is certain, perhaps we can, by examining mathematics, find which properties all certain knowledge must have. One such application of the "fact of mathematical certainty" was its use to solve what in the sixteenth century was called the problem of the criterion [43, Chapter I]. If there is only one system of thought around, people might well accept that one as true-as many Catholics did about the teachings of the Church in the Middle Ages. But then the Reformation developed alternative religious systems, and the Renaissance rediscovered the thought of pagan antiquity. Now the problem of finding the criterion that identified the true system became acute. In the seventeenth and eighteenth centuries, many thinkers looked to mathematics to help find an answer. What was the sign of the certainty of the conclusions of mathematics? The fact that nobody disputed them $[43$, Chapter VII]. Distinguishing mathematics from religion and philosophy, Voltaire wrote, "There are no sects in geometry. One does not speak of a Euclidean, an Archimedean" [49, Article "Sect."]. What every reasonable person agrees upon-that is the truth. How can this be applied to religion? Some religions forbid eating beef, some forbid eating pork; therefore, since they disagree, they both are wrong. But, continues Voltaire, all religions agree that one should worship God and be just; that must therefore be true. "There is but one morality," says Voltaire, "as there is but one geometry” [49, Miscellany, p. 225].

3. Applicability Let us turn now from the certainty of mathematics to its applicability. Since applying mathematics to describe the world works so well, thinkers who reflect on the applicability of mathematics find that it affects their views not only about thought, but also about the world. For Plato, the applicability of mathematics occurs because this world is merely an approximation to the higher mathematical reality; even the motions of the planets were inferior to pure mathematical motions [41, 529d]. For Aristotle, on the other hand, mathematical objects are just abstracted from the physical world by the intellect. A typical mathematically-based science is optics, in which we study physical objects - rays of light-as though they were mathematical straight lines [Physics II, Chapter 2; 194a]. We can thus use all the tools of geometry in that science of optics, but it is the light that is real.

One might think that Plato is a dreamer and Aristotle a hard-headed practical man. 
But today's engineer steeped in differential equations is the descendant of the dreamer. From Plato-and his predecessors the Pythagoreans who taught that "all is number" - into the Renaissance, many thinkers looked for the mathematical reality beyond the appearances. So did Copernicus, Kepler, and Galileo [7, Chapters 3, 5, 6]. The Newtonian world-system that completed the Copernican revolution was embodied in a mathematical model, based on the laws of motion and inverse-square gravitation, and set in Platonically absolute space and time ([6]; cf. [7, Chapter 7]). The success of Newtonian physics not only strongly reinforced the view that mathematics was the appropriate language of science, but also strongly reinforced the emerging ideas of progress and of truth based on universal agreement.

Another consequence of the Newtonian revolution was Newton's explicit help to theology, strongly buttressing what was called the argument for God's existence from design. The mathematical perfection of the solar system-elliptical orbits nearly circular, planets moving all in the same plane and direction-could not have come about by chance, said Newton, but "from the counsel and dominion of an intelligent and powerful Being" [37, General Scholium, p. 544]. "Natural theology," as this doctrine was called, focussed on examples of design and adaptation in nature, inspiring considerable research in natural history, especially on adaptation, research which was to play a role in Darwin's discovery of evolution by natural selection [14, pp. 263-266].

Just as the "fact of mathematical certainty" made certainty elsewhere seem achievable, so the "fact of mathematical applicability" in physical science inspired the pioneers of the idea of social science, Auguste Comte and Adolphe Quetelet. Both Comte and Quetelet were students of mathematical physics and astronomy in the early nineteenth century; Comte, while a student at the École polytechnique in Paris, was particularly inspired by Lagrange, Quetelet, and Laplace. Lagrange's great Analytical Mechanics was an attempt to reduce all of mechanics to mathematics. Comte went further: if physics was built on mathematics, so was chemistry built on physics, biology on chemistry, psychology on biology, and finally his own new creation, sociology (the term is his) would be built on psychology [ 8 , Chapter II]. The natural sciences were no longer (as they had once been) theological or metaphysical; they were what Comte called "positive"-based only on observed connections between things. Social science could now also become positive. Comte was a reformer, hoping for a better society through understanding what he called "social physics." His philosophy of positivism influenced twentieth-century logical positivism, and his ideas on history-"social dynamics"-influenced Feuerbach and Marx [32, Chapter 4]. Still, Comte only prophesied but did not create quantitative social science; this was done by Quetelet.

For Quetelet's conception of quantitative social science, the fact of applicability of mathematics was crucial. "We can judge of the perfection to which a science has come," he wrote in 1828, "by the ease with which it can be approached by calculation" (quoted in [27, p. 250]). Quetelet noted that Laplace had used probability and statistics in determining planetary orbits; Quetelet was especially impressed by what we call the normal curve of errors. Quetelet found empirically that many human traits-height, for instance-gave rise to a normal curve. From this, he defined the statistical concept, and the term, “average man" (homme moyen). Quetelet's work demonstrates that, just as the Platonic view that geometry underlies reality made mathematical physics possible, so having a statistical view of data is what makes social science possible.

Quetelet found also that many social statistics - the number of suicides in Belgium, 
for instance, or the number of murders-produced roughly the same figures every year. The constancy of these rates over time, he argued, dictated that murder or suicide had constant social causes. Quetelet's discovery of the constancy of crime rates raised an urgent question: whether the individuals are people or particles, do statistical laws say anything about individuals? or are the individuals free?

Laplace, recognizing that one needed probability to do physics, said that this fact did not mean that the laws governing the universe were ultimately statistical. In ignorance of the true causes, Laplace said, people thought that events in the universe depended on chance, but in fact all is determined. To an infinite intelligence which could comprehend all the forces in nature and the "respective situation of the beings who composed it," said Laplace, "nothing would be uncertain" [28, Chapter II]. Similarly, Quetelet held that "the social state prepares these crimes, and the criminal is merely the instrument to execute them" [27].

Another view was held by James Clerk Maxwell. In his work on the statistical mechanics of gases, Maxwell argued that statistical regularities in the large told you nothing about the behavior of individuals in the small [33, Chapter 22, pp. 315-16]. Maxwell seems to have been interested in this point because it allowed for free will. And this argument did not arise from Maxwell's physics; he had read and pondered the work of Quetelet on the application of statistical thinking to society [44]. The same sort of dispute about the meaning of probabilistically-stated laws has of course recurred in the twentieth-century philosophical debates over the foundations of quantum mechanics.

Thus discussions of basic philosophical questions - is the universe an accident or a divine design? is there free will or are we all programmed? - owe surprisingly much to the applicability of mathematics.

4. More than one geometry? Given the centrality of mathematics to western thought, what happens when prevailing views of the nature of mathematics change? Other things must change too. Since geometry had been for so long the canonical example both of the certainty and of the applicability of mathematics, the rise of non-Euclidean geometry was to have profound effects.

As is well known, in attempts to prove Euclid's parallel postulate and thus, as Saccheri put it in 1733, remove the single blemish from Euclid, mathematicians deduced a variety of surprising consequences from denying that postulate. Gauss, Bolyai, and Lobachevsky in the early nineteenth century each separately recognized that these consequences were not absurd, but rather were valid results in a consistent, non-Euclidean (Gauss's term) geometry.

Recall that Kant had said that space (by which he meant Euclidean 3-space) was the form of all our perceptions of objects. Hermann von Helmholtz, led in mid-century to geometry by his interest in the psychology of perception, asked whether Kant might be wrong: could we imagine ordering our perceptions in a non-Euclidean space? Yes, Helmholtz said. Consider the world as reflected in a convex mirror. Thus, the question of which geometry describes the world is no longer a matter for intuition -or for self-evident assumptions-but for experience [20].

What did this view-expressed as well by Bernhard Riemann and W. K. Clifford, among others - do to the received accounts of the relation between mathematics and the world? It detached mathematics from the world. Euclidean and non-Euclidean geometry give the first clear-cut historical example of two mutually contradictory mathematical structures, of which at most one can actually represent the world. This seems to indicate that the choice of mathematical axioms is one of intellectual freedom, not empirical constraint; this view, reinforced by Hamilton's discovery of a 
non-commutative algebra, suggested that mathematics is a purely formal structure, or as Benjamin Peirce put it, "Mathematics is the science which draws necessary conclusions," [40] - not the science of number (even symbolic algebra had been just a generalized science of number) or the science of space. Now that the axioms were no longer seen as necessarily deriving from the world, the applicability of mathematics to the world became turned upside down. The world is no longer, as it was for Plato, an imperfect model of the true mathematical reality; instead, mathematics provides a set of different models for one empirical reality. In 1902 the physicist Ludwig Boltzmann expressed a view which had become widely held: that models, whether physical or mathematical, whether geometric or statistical, had become the means by which the sciences "comprehend objects in thought and represent them in language" [3]. This view, which implies that the sciences are no longer claiming to speak directly about reality, is now widespread in the social sciences as well as the natural sciences, and has transformed the philosophy of science. As applied to mathematics itself-the formal model of mathematical reasoning-it has resulted in Gödel's demonstration that one can never prove the consistency of mathematics, and the resulting conclusion among some philosophers that there is no certainty anywhere, not even in mathematics [2, p. 206].

5. Opposition The best proof of the centrality of mathematics is that every example of its influence given so far has provoked strong and significant opposition. Attacks on the influence of mathematics have been of three main types. Some people have simply favored one view of mathematics over other views; other people have granted the importance of mathematics but have opposed what they consider its overuse or extension into inappropriate domains; still others have attacked mathematics, and often all of science and reason, as cold, inhuman, or oppressive.

Aristotle's reaction against Platonism is perhaps the first example of opposition to one view of mathematics (eternal objects) while championing another (deductive method). Another example is Newton's attack on Descartes's attempt to use nothing but "self-evident" assumptions to figure out how the universe worked. There are many mathematical systems God could have used to set up the world, said Newton. One could not decide a priori which occurs; one must, he says, observe in nature which law actually holds. Though mathematics is the tool one uses to discover the laws, Newton concludes that God set up the world by free choice, not mathematical necessity [35, pp. $7-8][36$, p. 47]. This point is crucial to Newton's natural theology: that the presence of order in nature proves that God exists.

Another example of one view based on mathematics attacking another can be found in Malthus's Essay on Population of 1798. He accepts the Euclidean deductive model -in fact he begins with two "postulata": man requires food, and the level of human sexuality remains constant [31, Chapter I]. His consequent analysis of the growth of population and of food supply rests on mathematical models. Nonetheless, one of Malthus's chief targets is the predictions by Condorcet and others of continued human progress modelled on that of mathematics and science. As in Newton's attack on Descartes, Malthus applied one view of mathematics to attack the conclusions others claimed to have drawn from mathematics.

Our second category of attacks-drawing a line that mathematics should not cross -is exemplified by the seventeenth-century philosopher and mathematician Blaise Pascal. Reacting against Cartesian rationalism, Pascal contrasted the "esprit géometrique" (abstract and precise thought) with what he called the "esprit de finesse" (intuition) [39, Pensée 1] holding that each had its proper sphere, but that 
mathematics had no business outside its own realm. "The heart has its reasons," wrote Pascal, "which reason does not know" [39, Pensée 277]. Nor is this contradicted by the fact that Pascal was willing to employ mathematical thinking for theological purposes - recall his "wager" argument to convince a gambling friend to try acting like a good Catholic [39, Pensée 233]; the point here was to use his friend's own probabilistic reasoning style in order to convince him to go on to a higher level.

Similarly, the mathematical reductionism of men like Lagrange and Comte was opposed by men like Cauchy. Cauchy, whom we know as the man who brought Euclidean rigor to the calculus, opposed both Lagrange's attempt to reduce mechanics to calculus and calculus to formalistic algebra [15, pp. 51-54], and opposed the positivists' attempt to reduce the human sciences to an ultimately mathematical form. "Let us assiduously cultivate the mathematical sciences," Cauchy wrote in 1821, but "let us not imagine that one can attack history with formulas, nor give for sanction to morality theorems of algebra or integral calculus" [5, p. vii]. Analogously, in our own day, computer scientist Joseph Weizenbaum attacks the modern, computer-influenced view that human beings are nothing but processors of symbolic information, arguing that the computer scientist should "teach the limitations of his tools as well as their power" [50, p. 277].

Finally, we have those who are completely opposed to the method of analysis, the mathematization of nature, and the application of mathematical thought to human affairs. Witness the Romantic reaction against the Enlightenment: Goethe's opposition to the Newtonian analysis of white light, or, even more extreme, William Wordsworth in The Tables Turned:

Sweet is the lore which Nature brings;

Our meddling intellect

Mis-shapes the beauteous forms of things:-

We murder to dissect.

Again, Walt Whitman, in his poem "When I heard the learn'd astronomer," describes walking out on the lecture on celestial distances, having become "tired and sick," going outside instead to look "up in perfect silence at the stars."

Reacting against statistical thinking on behalf of the dignity of the individual, Charles Dickens in his 1854 novel Hard Times satirizes a "modern school” in which a pupil is addressed as "Girl number twenty" [12, Book I, Chapter II]; the schoolmaster's son betrays his father, justifying himself by pointing out that in any given population a certain percentage will become traitors, so there is no occasion for surprise or blame [12, Book III, Chapter VII]. In a more political point, Dickens through his hero denounces the analytically-based efficiency of industrial division of labor, saying it regards workers as though they were nothing but "figures in a sum" [12, Book II, Chapter V].

The Russian novelist Evgeny Zamyatin, in his early-twentieth-century antiutopian novel We (a source for Orwell's 1984), envisions individuals reduced to being numbers, and mathematical tables of organization used as instruments of social control. Though the certainty of mathematics, and thus its authority, has sometimes been an ally of liberalism, as we have seen in the cases of Voltaire and Condorcet, Zamyatin saw how it could also be used as a way of establishing an unchallengeable authority, as philosophers like Plato and Hobbes had tried to use it, and he wanted no part of it.

6. Conclusion As the battles have raged in the history of Western thought, mathe- 
matics has been on the front lines. What does it all (to choose a phrase) add up to?

My point is not that what these thinkers have said about mathematics is right, or is wrong. But this history shows that the nature of mathematics has been-and must be - taken into account by anyone who wants to say anything important about philosophy or about the world. I want, then, to conclude by advocating that we teach mathematics not just to teach quantitative reasoning, not just as the language of science-though these are very important-but that we teach mathematics to let people know that one cannot fully understand the humanities, the sciences, the world of work, and the world of man without understanding mathematics in its central role in the history of Western thought.

Acknowledgements. I thank the students in my Mathematics 1 classes at Pomona and Pitzer Colleges for stimulating discussions and suggestions on some of the topics covered in this paper, especially David Bricker, Maria Camareña, Marcelo D'Asero, Rachel Lawson, and Jason Gottlieb. I also thank Sandy Grabiner for both his helpful comments and his constant support and encouragement.

\section{REFERENCES}

1. Charles Babbage, On the Economy of Machinery, Charles Knight, London, 1832.

2. William Barrett, Irrational Man: A Study in Existential Philosophy, Doubleday, New York, 1958. Excerpted in William L. Schaaf, ed., Our Mathematical Heritage, Collier, New York, 1963.

3. Ludwig Boltzmann, Model, Encyclopedia Britannica, 1902.

4. Carl Boyer, History of Analytic Geometry, Scripta Mathematica, New York, 1956.

5. A.-L. Cauchy, Cours d'analyse, 1821. Reprinted in A.-L. Cauchy, Oeuvres, series 2, vol. 3, GauthierVillars, Paris, 182.

6. I. Bernard Cohen, The Newtonian Revolution, Cambridge University Press, Cambridge, 1980.

7. , The Birth of a New Physics, 2d edition. W. W. Norton, New York and London, 1985.

8. Auguste Comte, Cours de philosophie positive, vol. I, Bachelier, Paris, 1830.

9. Marquis de Condorcet, Sketch for a Historical Picture of the Progress of the Human Mind, 1793, tr, June Barraclough. In Keith Michael Baker, ed., Condorcet: Selected Writings. Bobbs-Merrill, Indianapolis, 1976.

10. René Descartes, Discourse on Method, 1637, tr. L. J. Lafleur, Liberal Arts Press, New York, 1956.

11. __ La géométrie, 1637, tr., D. E. Smith and Marcia L. Latham, The Geometry of René Descartes, Dover, NY, 1954.

12. Charles Dickens, Hard Times, 1854. Norton Critical Edition edited by George Ford and Sylvere Monod, W. W. Norton, New York and London, 1966.

13. Neal C. Gillespie, Charles Darwin and the Problem of Creation, University of Chicago Press, Chicago and London, 1979.

14. Charles C. Gillespie, The Edge of Objectivity, Princeton University Press, Princeton, NJ, 1960.

15. Judith V. Grabiner, The Origins of Cauchy's Rigorous Calculus, M.I.T. Press, Cambridge, Mass., 1981.

16. John C. Greene, Science, Ideology, and World View: Essays in the History of Evolutionary Ideas, University of California Press, Berkeley, 1981.

17. A. Rupert Hall, From Galileo to Newton, 1630-1720. Harper and Row. New York and Evanston. 1963.

18. T. L. Heath (Editor), The Works of Archimedes with the Method of Archimedes, New York, n.d.

19. , The Thirteen Books of Euclid's Elements, Volume I, Cambridge University Press, 1925, reprinted by Dover, New York, 1956.

20. Hermann von Helmholtz, On the origin and significance of geometrical axioms, 1870, reprinted in Hermann von Helmholtz, Popular Scientific Lectures, edited by Morris Kline, Dover, NY, 1962.

21. Thomas Hobbes, Leviathan, or the Matter, Form, and Power of a Commonwealth, Ecclesiastical and Civil, 1651, in E. Burtt, ed., The English Philosophers from Bacon to Mill, Modern Library, New York, 1939.

22. Anthony Hyman, Charles Babbage: Pioneer of the Computer. Princeton University Press, Princeton, NJ, 1982.

23. Werner Jaeger, Early Christianity and Greek Paideia, Oxford University Press, London, Oxford, and New York, 1961.

24. Immanuel Kant, Critique of Pure Reason, 1781, tr. F. Max Müller, Macmillan, New York, 1961.

25. __ Prolegomena to Any Future Metaphysics, 1783, ed. Lewis W. Beck, Liberal Arts Press, New York, 1951.

26. Morris Kline, Mathematics in Western Culture, Oxford University Press, New York, 1953. 
27. D. Landau and P. Lazarsfeld, Quetelet, International Encyclopedia of the Social Sciences, Vol. 13, Macmillan, New York, 1968, pp. 247-257.

28. Pierre Simon Laplace, A Philosophical Essay on Probabilities, 1819 tr. F. W. Truscott and F. L. Emory, Dover, NY, 1951.

29. Desmond Lee, 1965 Introduction, in Desmond Lee, ed., Plato: Timaeus and Critias, Penguin Books of Great Britain, London, 1971.

30. Leibniz, Preface to the General Science and Towards a Universal Characteristic; 1677; reprint, Selections, Philip P. Weiner, editor, 1951, pp. 12-17, 17-25.

31. Thomas R. Malthus, An Essay on the Principle of Population, as it Affects the Future Improvement of Society: with Remarks on the Speculations of Mr. Godwin, M. Condorcet, and other writers, 1798, in Garrett Hardin, ed., Population, Evolution and Birth Control, Freeman, San Francisco, 1964, pp. 4-16.

32. Maurice Mandelbaum, The Search for a Science of Society: From Saint-Simon to Marx and Engels, Chapter 4 in Maurice Mandelbaum, History, Man, and Reason, Johns Hopkins University Press, Baltimore and London, 1971, pp. 63-76.

33. James Clerk Maxwell, Theory of Heat, Longmans, Green, \& Co., London, 1871.

34. Seyyed Hossein Nasr, Science and Civilization in Islam, New American Library, New York, Toronto and London, 1968.

35. Isaac Newton, Letter to Henry Oldenburg, July, 1672, in [38].

36. L_ Letter to Richard Bentley, December 10, 1692, in [38].

37. Sir Isaac Newton's Mathematical Principles of Natural Philosophy and His System of the World, tr. Andrew Motte, revised and edited by Florian Cajori, University of California Press, Berkeley, 1934.

38. __ Newton's Philodophy of Nature: Selections from His Writings, ed. H. S. Thayer, Hafner, New York, 1951.

39. Blaise Pascal, Pensées, E. P. Dutton, New York, 1958.

40. Benjamin Peirce, Linear Associative Algebra, Amer. J. Math., 4 (1881).

41. Plato, Republic, tr. A. D. Lindsay, E. P. Dutton, New York, 1950.

42. Plato, Timaeus, in [29].

43. Richard H. Popkin, The History of Scepticism from Erasmus to Spinoza, University of California Press, Berkeley and Los Angeles, 1979.

44. Theodore M. Porter, A Statistical Survey of Gases: Maxwell's Social Physics, Historical Studies in the Physical Sciences 12 (1981), 77-116.

45. A. Quetelet, Instructions populaires sur le calcul des probabilités, Tarlier, Brussels, 1828.

46. Bertrand Russell, A Critical Exposition of the Philosophy of Leibniz, 2d edition, Allen and Unwin, London, 1937.

47. William G. Sinnigen and Arthur E. R. Boak, A History of Rome to A.D. 565, sixth edition, Macmillan, New York, 1977.

48. Andrew Skinner, Introduction, Adam Smith, The Wealth of Nations, (1776), Penguin Books, London, 1974, pp. 11-97.

49. Benedict de Spinoza, Ethics, preceded by On the Improvement of the Understanding, ed. James Gutmann, Hafner, New York, 1953.

50. François-Marie Arouet de Voltaire, The Portable Voltaire, The Viking Press, New York, 1949, selections from Dictionnaire Philosophique (1764), pp. 53-228.

51. Joseph Weizenbaum, Computer Power and Human Reason: From Judgment to Calculation, Freeman, San Francisco, 1976.

52. Harry Austryn Wolfson, What is New in Philo?, in Harry A. Wolfson, From Philo to Spinoza: Two Studies in Religious Philosophy, Behrman House, New York, 1977.

Some of the greatest advances in mathematics have been due to the invention of symbols, which it afterwards became necessary to explain; from the minus sign proceeded the whole theory of negative quantities.

Aldous Huxley, Jesting Pilate, London, Chatto and Windus, 1926 